\section{(6) OPEN ACCESS}

\title{
Impact of social and technological distraction on pedestrian crossing behaviour: an observational study
}

\author{
Leah L Thompson, ${ }^{1}$ Frederick P Rivara, ${ }^{1}{ }^{1,3}$ Rajiv C Ayyagari, ${ }^{1}$ Beth E Ebel ${ }^{1,2,3}$
}

\begin{abstract}
- Additional supplementary files are published online only. To view these files please visit the journal online (http://dx.doi. org/10.1136/injuryprev-2012040601).
\end{abstract}

${ }^{1}$ Harborview Injury Prevention \& Research Center, University of Washington, Seattle, Washington, USA

${ }^{2}$ Department of Pediatrics, University of Washington, Seattle, Washington, USA ${ }^{3}$ Seattle Children's Hospital and Seattle Children's Research Institute, Seattle, Washington, USA

Correspondence to Dr Beth E Ebel, Harborview Injury Prevention \& Research Center, University of Washington, 325 Ninth Ave, Box 359960, Seattle, Washington 98104-2499, USA bebel@uw.edu

Accepted 2 November 2012 Published Online First 13 December 2012

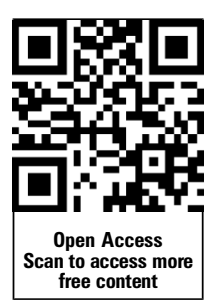

\begin{abstract}
Objectives The objective of the present work was to study the impact of technological and social distraction on cautionary behaviours and crossing times in pedestrians.

Methods Pedestrians were observed at 20 high-risk intersections during 1 of 3 randomly assigned time windows in 2012. Observers recorded demographic and behavioural information, including use of a mobile device (talking on the phone, text messaging, or listening to music). We examined the association between distraction and crossing behaviours, adjusting for age and gender. All multivariate analyses were conducted with random effect logistic regression (binary outcomes) and random effect linear regression (continuous outcomes), accounting for clustering by site.
\end{abstract}

Results Observers recorded crossing behaviours for 1102 pedestrians. Nearly one-third (29.8\%) of all pedestrians performed a distracting activity while crossing. Distractions included listening to music (11.2\%), text messaging $(7.3 \%)$ and using a handheld phone (6.2\%). Text messaging, mobile phone use and talking with a companion increased crossing time. Texting pedestrians took 1.87 additional seconds $(18.0 \%)$ to cross the average intersection (3.4 lanes), compared to undistracted pedestrians. Texting pedestrians were 3.9 times more likely than undistracted pedestrians to display at least 1 unsafe crossing behaviour (disobeying the lights, crossing mid-intersection, or failing to look both ways). Pedestrians listening to music walked more than half a second (0.54) faster across the average intersection than undistracted pedestrians.

Conclusions Distracting activity is common among pedestrians, even while crossing intersections. Technological and social distractions increase crossing times, with text messaging associated with the highest risk. Our findings suggest the need for intervention studies to reduce risk of pedestrian injury.

\section{INTRODUCTION}

Motor vehicle-pedestrian crashes remain a significant source of serious injury, with an estimated 60000 pedestrians injured and 4000 killed per year in the USA. ${ }^{1}$ Globally, pedestrians and other vulnerable road users account for almost half of road traffic deaths. ${ }^{2}$ In Washington, as in most US states, traffic laws require that vehicles yield to pedestrians in crosswalks and at intersections. ${ }^{3} 4$ Although the law assigns pedestrians the right of way, it does not relieve pedestrians of looking out for their own safety. Cautionary behaviours include using sidewalks and crosswalks when available, obeying traffic signals and looking both ways before entering the street.

While poor intersection design and dangerous driving account for some pedestrian fatalities, a recent study found that actions by pedestrians may account for as much as $15 \%$ of all deaths. ${ }^{5}$ In a study from Vancouver (British Columbia, Canada), 21\% of pedestrians observed committed one or more crossing violations. ${ }^{6}$

Distracted walking, like distracted driving, is likely to increase in parallel with the penetration of electronic devices into the consumer market. As of 2011, there were more phones than people in the USA, and internationally, the number of mobile phone subscriptions is an estimated 5.9 billion. $^{7-9}$ Distraction has been more frequently studied among drivers than pedestrians; up to $28 \%$ of driver crash risk is attributable to distraction from cell phone use or text messaging. ${ }^{10}$ Talking on the phone, texting, using an MP3 player or adjusting vehicle music controls diminish driver focus and increase the risk of a crash. ${ }^{11-18}$ Among drivers, cohort studies indicate that the use of voice/text devices is associated with crash risks ranging from 4-23 times above baseline levels. ${ }^{19}$

Less is known about the impact of distraction on pedestrian behaviour or risk. Pedestrians tend to act less cautiously when distracted, whether by cellphones, music players, food, or other people. ${ }^{52}-22$ Studies of distracted pedestrians have primarily focused on the behaviour of selected subjects in a simulated environment. ${ }^{22-25}$ Simulated environments offer more control of conditions and capture demographic and behavioural background on participants. However, removing pedestrians from their natural environment and making them aware of the focus on their walking behaviour may alter their actions. The few studies that have occurred in real environments have focused on individual locations, age groups, or distractions, or have tracked violations without examining their relationship to distracted walking. ${ }^{520}$ We sought to expand on prior research by studying distracting behaviours in a large group of pedestrians during the act of crossing the street.

\section{METHODS}

\section{Setting}

We conducted a prospective observational study of pedestrian behaviour at intersections in Seattle, Washington in the summer of 2012. We chose the 20 intersections with the highest number of pedestrian injuries during the prior 3 years, based on data from the Seattle Department of 
Transportation. The study was reviewed and deemed exempt by the Seattle Children's Hospital institutional review board.

In order to maximise the flow of pedestrians at each intersection and observe a variety of pedestrians, three observation time windows were selected: 8:00-9:00 (morning commute), 12:00-13:00 (lunch break) and 16:00-17:00 (afternoon commute). We assigned each intersection to an observational time slot using random number generation. Data collection sheets were created for each intersection, mapping compass directions and landmarks.

\section{Population}

At each intersection, two observers recorded pedestrian crossing behaviour for every pedestrian meeting the selection criteria. At each intersection of two streets, there were eight typical directions a pedestrian could walk. Each observer watched a given direction for $15 \mathrm{~min}$ and then rotated, to cover eight crossing directions in the span of the hour. Given the traffic activity at these high-risk intersections, crossing on the diagonal was almost never observed. To avoid possible selection bias, each observer carried a timer that vibrated once per minute. The observer recorded data for the first person who reached the curb after the timer went off. In cases where two individuals arrived completely simultaneously at the curb following the timer, the first person to step off the curb was selected as the 'index pedestrian'.

\section{Data collection}

Traffic volume data and collision data were obtained from the Seattle Department of Transportation. The width of the street was obtained by manually measuring the distances using a rolling measuring device. The number of lanes crossed for each street was recorded. Examples of data collection tools are available in appendices $1-3$.

All observations were completed by two trained observers. Observers recorded demographic and behavioural information for each pedestrian. The demographic information recorded included the gender and estimated age of the pedestrian. The age categories were <18, 18-24, 25-44, 45-64 and 65+ years.

Observers additionally recorded whether the pedestrian was alone, in a group, or in a group talking to another person. Individuals were counted as being in a group if they appeared to be in a social interaction with another individual at the crosswalk, for example, holding hands. If an individual was talking to another person while crossing, they were counted as 'group talking'.

For behaviours, the observer recorded the direction the pedestrian walked, whether the pedestrian crossed at the crosswalk, whether the pedestrian looked left and right, and whether he or she obeyed the intersection signal (if present). Crossing in the crosswalk meant that the pedestrian took no more than one step outside the painted crosswalk lines. Looking left and right meant that the observer had to see a noticeable turn of the chin left and right immediately prior to the pedestrian stepping into the roadway. Obeying the lights meant the pedestrian entered the street when the walk signal was lit. Pedestrians who entered the street after the 'don't cross' indicator had begun to flash were counted as disobeying the signal.

Observers also noted whether the pedestrian was using a mobile phone (phone to ear or earpiece), music player (earphones), or texting (manual use of mobile device) while crossing. Individuals with headphones in their ears connected to a device capable of playing music were counted as listening to music. The observer recorded the time it took each pedestrian to cross the intersection, measuring from the time both feet entered the street, to the time both feet stepped onto the sidewalk.

\section{Analysis}

All data were entered into an Excel spreadsheet (Microsoft, Redmond, Washington, USA) and Stata 11 (Stata Statistical Software, College Station, Texas, USA) was used for data analysis.

Pedestrian distractions were categorised as follows: listening to music (headphones), handheld mobile phone, earpiece mobile phone, text messaging and talking with another person. Additional distractions (eg, carrying baby, pushing a stroller) were categorised as 'other'. Age 18-24 was considered the reference category.

We examined the association between pedestrian crossing time (lane crossing time in seconds) and pedestrian distraction, adjusted for key confounders (age, gender). Next, we examined the association between pedestrian crossing behaviours (cross at crosswalk, obey lights, look both ways) and pedestrian distraction, adjusted for key confounders (age, gender). Finally, we examined the association between optimal pedestrian behaviour (crossed at crosswalk, obeyed lights, looked both ways) and pedestrian distraction. All multivariate analyses were conducted with random effect logistic regression (binary outcomes) and random effect linear regression (continuous outcomes), accounting for clustering by site.

\section{RESULTS}

Observers recorded crossing behaviours of 1102 pedestrians at intersections, with a mean of 55 observations at each site (range 19-88). Though observation times were randomly distributed among observation sites, nearly half of pedestrians (46.6\%) were observed walking from 8:00-9:00 reflecting higher pedestrian density in the morning hours (table 1 ). The majority $(54.3 \%)$ of pedestrians were in the $25-44$ year age category. Slightly more than half the pedestrians observed were male. Nearly $80 \%$ of the pedestrians observed walked alone. Most pedestrians obeyed the lights $(80.0 \%)$ and crossed at the crosswalk $(94.4 \%)$, but only one-third $(34.9 \%)$ of pedestrians looked left and right prior to entering the roadway. Approximately $30 \%$ of all pedestrians observed performed a distracting activity while crossing. Distractions while in the roadway included listening to music (11.2\%), text messaging (7.3\%) and using a handheld phone $(6.2 \%)$ (table 1$)$.

\section{Crossing times}

Distracted pedestrians took significantly longer to cross the intersection (table 2). The mean crossing time for an undistracted individual was $10.4 \mathrm{~s}$. Across the average intersection length of 3.4 lanes, individuals using a handheld or hands-free phone took an additional 0.75 and 1.29 s to cross, respectively. Pedestrians who were text messaging took over half a second longer to cross each lane $(0.55 \mathrm{~s}, 95 \%$ CI 0.36 to 0.75$)$, adding an extra $18.0 \%$ to total crossing time. Pedestrians listening to music walked faster than undistracted pedestrians, by an average of $0.16 \mathrm{~s}$ per lane. Females walked slower than males, as did individuals talking in a group, compared to their counterparts who walked alone. Finally, as age increased, crossing time per lane also increased, with pedestrians 65 and older walking nearly a full second slower per lane than the reference group, 18-24 year olds (table 2) 
Table 1 Site characteristics and pedestrian characteristics, $(n=1102)$

\begin{tabular}{|c|c|c|}
\hline Characteristic & $\%$ & n \\
\hline \multicolumn{3}{|c|}{ Pedestrian characteristics: } \\
\hline \multicolumn{3}{|l|}{ Observed time period } \\
\hline $8: 00-9: 00$ & 46.6 & 514 \\
\hline 12:00-13:00 & 28.6 & 315 \\
\hline 16:00-17:00 & 24.8 & 273 \\
\hline \multicolumn{3}{|l|}{ Age group } \\
\hline$<18$ years & 3.09 & 34 \\
\hline $18-24$ years & 18.8 & 207 \\
\hline $25-44$ years & 54.3 & 598 \\
\hline $45-64$ years & 19.2 & 212 \\
\hline $65+$ years & 4.6 & 51 \\
\hline \multicolumn{3}{|l|}{ Gender } \\
\hline Female & 45.8 & 505 \\
\hline Male & 54.2 & 597 \\
\hline \multicolumn{3}{|l|}{ Distraction } \\
\hline None & 70.3 & 775 \\
\hline Handheld phone & 6.2 & 68 \\
\hline Hands-free phone & 1.8 & 20 \\
\hline Text messaging & 7.3 & 80 \\
\hline Listening to music & 11.2 & 123 \\
\hline Other & 3.3 & 36 \\
\hline \multicolumn{3}{|l|}{ Social } \\
\hline Alone & 80.0 & 877 \\
\hline \multicolumn{3}{|c|}{ Walking with other(s) } \\
\hline Not talking & 8.4 & 92 \\
\hline Talking & 12.1 & 133 \\
\hline \multicolumn{3}{|l|}{ Cross at crosswalk } \\
\hline Yes & 94.4 & 1040 \\
\hline No & 4.2 & 46 \\
\hline NA & 1.5 & 16 \\
\hline \multicolumn{3}{|l|}{ Obey lights } \\
\hline Yes & 84.6 & 932 \\
\hline No & 12.2 & 134 \\
\hline NA & 3.3 & 36 \\
\hline \multicolumn{3}{|c|}{ Look left and right prior to crossing } \\
\hline Yes & 34.9 & 385 \\
\hline No & 65.1 & 717 \\
\hline \multicolumn{3}{|l|}{ Site characteristics: } \\
\hline \multicolumn{3}{|l|}{ Number of lanes } \\
\hline 2 & 14.4 & 159 \\
\hline 3 & 44.7 & 492 \\
\hline 4 & 27.6 & 304 \\
\hline 5 & 12.5 & 138 \\
\hline 6 & 0.3 & 3 \\
\hline 7 & 0.5 & 6 \\
\hline
\end{tabular}

NA, not applicable.

\section{Crossing behaviours}

Some forms of distraction were also associated with risky pedestrian behaviour (table 3). Pedestrians who were texting were significantly more likely to cross the street without looking both ways before crossing ( $\mathrm{OR}=4.00,95 \%$ CI 2.04 to 7.84 ). Listening to music ( $O R=1.69,95 \%$ CI 1.06 to 2.66), talking with others $(\mathrm{OR}=1.69,95 \% \mathrm{CI} 1.08$ to 2.59$)$ and 'other distractions' ( $\mathrm{OR}=2.86,95 \% \mathrm{CI} 1.19$ to 6.98 ) were also associated with failure to look both ways. Nearly one-third of the 'other distractions' observed involved interactions with a child or a pet. Talking on the phone was not associated with failure to look both ways before crossing the street.

Female pedestrians, whether distracted or not, were somewhat less likely to look both ways before crossing the street.
Table 2 Impact of distraction, gender and age on time to cross per lane (in seconds) $(n=1102)$

\begin{tabular}{lrrr}
\hline & $\boldsymbol{\beta}$ Coefficient & \multicolumn{1}{l}{$\mathbf{9 5 \%} \mathbf{C l}$} & $\mathbf{p}$ Value \\
\hline Distraction & & & \\
Using handheld phone & $\mathbf{0 . 2 2}$ & $\mathbf{0 . 0 1}$ to $\mathbf{0 . 4 3}$ & $\mathbf{0 . 0 4}$ \\
Using hands-free phone & $\mathbf{0 . 3 8}$ & $\mathbf{0 . 0 0}$ to $\mathbf{0 . 7 6}$ & $\mathbf{0 . 0 5}$ \\
Text messaging & $\mathbf{0 . 5 5}$ & $\mathbf{0 . 3 6}$ to $\mathbf{0 . 7 5}$ & $\mathbf{0 . 0 0}$ \\
Listening to music & $-\mathbf{0 . 1 6}$ & $-\mathbf{0 . 3 3}$ to 0.00 & $\mathbf{0 . 0 5}$ \\
Other & 0.21 & -0.08 to 0.50 & 0.15 \\
In a group, talking & $\mathbf{0 . 1 9}$ & $\mathbf{0 . 0 4}$ to $\mathbf{0 . 3 5}$ & $\mathbf{0 . 0 2}$ \\
Female gender & $\mathbf{0 . 1 4}$ & $\mathbf{0 . 0 4}$ to $\mathbf{0 . 2 4}$ & $\mathbf{0 . 0 1}$ \\
Age group & & & \\
$<18$ years & 0.09 & -0.25 to 0.42 & 0.61 \\
18-24 years & Ref. & & \\
25-44 years & 0.11 & -0.03 to 0.25 & 0.11 \\
45-64 years & $\mathbf{0 . 2 7}$ & $\mathbf{0 . 1 0}$ to $\mathbf{0 . 4 3}$ & $\mathbf{0 . 0 0}$ \\
65+ years & $\mathbf{0 . 8 7}$ & $\mathbf{0 . 6 0}$ to 1.13 & $\mathbf{0 . 0 0}$ \\
\hline Data in bold are significant to $\mathrm{p}<0.05$. For gender-specific data, males were the gender \\
reference group.
\end{tabular}

Distracting behaviours, age, gender, or social grouping, were not associated with the likelihood that a pedestrian crossed at the crosswalk or obeyed the lights, as most pedestrians followed these safety behaviours. However, pedestrians who obeyed the traffic signals were 2.8 times more likely not to look both ways (table 3 ).

Finally, we examined the association between distracting behaviours and optimal crossing behaviour, defined as looking both ways, crossing at the crosswalk and obeying the traffic signals (table 4). Only text messaging and gender had a significant effect on optimal crossing behaviour. Only $26 \%$ of pedestrians exhibited all three optimal crossing behaviours. Walkers who were text messaging were 3.9 times more likely to exhibit at least 1 unsafe crossing behaviour. Controlling for distracting behaviours, females were twice as likely to exhibit at least one unsafe crossing behaviour, relative to male counterparts.

\section{DISCUSSION}

Our study found that many pedestrians send text messages or use mobile devices while crossing the street. Use of these devices is associated with slower crossing times. Text messaging appears particularly risky. Texting is associated with an $18 \%$ increase in crossing times and failure to perform routine pedestrian safety behaviours before stepping into the roadway. This is the first published observational study with sufficient power to examine the impact of texting on real-world pedestrian behaviour. ${ }^{20}$ As was found by earlier observational studies of pedestrian behaviour, individuals talking on a cell phone crossed more slowly than those who were undistracted.

In our study, nearly $30 \%$ of pedestrians continued distracting behaviours in the intersection, a proportion somewhat higher than the $20 \%$ figure from an observational study conducted in $20055^{5}$ Pedestrians were chosen according to an algorithm to avoid risk of selection bias which may have been present in earlier studies. ${ }^{20} 21$ Fewer individuals were talking on mobile phones compared with a previous large observational trial which recorded the behaviour of all cell phone users to arrive at the crosswalk. ${ }^{20}$ This earlier study predated the widespread adoption of text messaging, and suggests changing patterns of mobile device use.

Laboratory studies have demonstrated that distractions impair pedestrian awareness of their surroundings. In simulation studies, children and college-age pedestrians behaved with less caution, experienced more 'hits' and close calls with virtual 
Table 3 Odds of unsafe pedestrian behaviour by distraction, gender and age $(n=1102)$

\begin{tabular}{|c|c|c|c|}
\hline & OR & $95 \% \mathrm{Cl}$ & p Value \\
\hline \multicolumn{4}{|c|}{ Not looking left and right: } \\
\hline \multicolumn{4}{|l|}{ Distraction } \\
\hline Handheld phone & 0.97 & 0.56 to 1.82 & 0.91 \\
\hline Hands-free phone & 0.94 & 0.37 to 2.44 & 0.91 \\
\hline Text messaging & 4.00 & 2.04 to 7.84 & 0.00 \\
\hline Listening to music & 1.69 & 1.06 to 2.66 & 0.03 \\
\hline Other & 2.86 & 1.19 to 6.98 & 0.02 \\
\hline In a group, talking & 1.69 & 1.08 to 2.59 & 0.02 \\
\hline Female gender & 1.69 & 1.27 to 2.20 & 0.00 \\
\hline \multicolumn{4}{|l|}{ Age group } \\
\hline$<18$ years & 1.23 & 0.52 to 2.94 & 0.64 \\
\hline \multicolumn{4}{|l|}{$18-24$ years } \\
\hline $25-44$ years & 1.30 & 0.90 to 1.86 & 0.16 \\
\hline $45-64$ years & 0.93 & 0.61 to 1.43 & 0.76 \\
\hline $65+$ years & 0.94 & 0.48 to 1.88 & 0.87 \\
\hline \multicolumn{4}{|c|}{ Not crossing at crosswalk: } \\
\hline \multicolumn{4}{|l|}{ Distraction } \\
\hline Handheld phone & 0.33 & 0.04 to 2.48 & 0.28 \\
\hline Hands-free phone & 1.11 & 0.14 to 9.12 & 0.91 \\
\hline Text messaging & 1.47 & 0.53 to 4.01 & 0.46 \\
\hline Listening to music & 1.75 & 0.79 to 3.94 & 0.16 \\
\hline Other & 1.43 & 0.31 to 6.62 & 0.65 \\
\hline In a group, talking* & - & - & - \\
\hline Gender & 0.71 & 0.38 to 1.34 & 0.29 \\
\hline \multicolumn{4}{|l|}{ Age group } \\
\hline$<18$ years & 1.11 & 0.22 to 5.70 & 0.90 \\
\hline \multicolumn{4}{|l|}{$18-24$ years } \\
\hline 25-44 years & 0.48 & 0.24 to 0.96 & 0.39 \\
\hline $45-64$ years & 0.40 & 0.15 to 1.07 & 0.07 \\
\hline $65+$ years & 0.33 & 0.04 to 2.66 & 0.30 \\
\hline \multicolumn{4}{|l|}{ Not obeying the lights: } \\
\hline \multicolumn{4}{|l|}{ Distraction } \\
\hline Handheld phone & 1.18 & 0.54 to 2.53 & 0.70 \\
\hline Hands-free phone & 0.90 & 0.20 to 4.10 & 0.90 \\
\hline Text messaging & 0.92 & 0.44 to 1.90 & 0.80 \\
\hline Listening to music & 1.33 & 0.76 to 2.36 & 0.32 \\
\hline Other & 1.06 & 0.38 to 2.97 & 0.90 \\
\hline In a group, talking & 0.76 & 0.39 to 1.52 & 0.45 \\
\hline Female gender & 0.72 & 0.49 to 1.06 & 0.10 \\
\hline Looking both ways & 2.78 & 1.84 to 4.22 & 0.00 \\
\hline \multicolumn{4}{|l|}{ Age group: } \\
\hline$<18$ years & 2.78 & 1.11 to 7.10 & 0.03 \\
\hline $18-24$ years & Ref. & & \\
\hline $25-44$ years & 0.72 & 0.44 to 1.17 & 0.19 \\
\hline $45-64$ years. & 0.72 & 0.39 to 1.34 & 0.30 \\
\hline $65+$ years & 0.34 & 0.10 to 1.22 & 0.10 \\
\hline
\end{tabular}

Data in bold are significant to $p<0.05$. For gender-specific data, males were the gender reference group.

${ }^{*}$ Too few subjects in this category to calculate an OR.

cars, and waited longer to cross than their undistracted counterparts, regardless of previous experience with mobile technology. ${ }^{22-25}$ Additionally, virtual studies of pedestrians corroborate our finding that text messaging increases high-risk pedestrian choices. $^{22}$

Individuals walking with music crossed more speedily than those with no distractions; previous studies suggest that a musical beat may alter the natural gait speed of an individual. ${ }^{26}$ Though music listeners crossed more quickly, they were less likely to look both ways before crossing the street. Additionally, we were surprised to find that females were less likely to display optimal crossing behaviour than males, because males
Table 4 Odds of failing to display optimal crossing behaviour $(n=1102)$

\begin{tabular}{|c|c|c|c|}
\hline & OR & $95 \% \mathrm{Cl}$ & $\overline{\text { p Value }}$ \\
\hline \multicolumn{4}{|l|}{ Distraction } \\
\hline Using handheld phone & 0.83 & 0.46 to 1.48 & 0.53 \\
\hline Using hands-free phone & 0.90 & 0.33 to 2.46 & 0.84 \\
\hline Text messaging & 3.85 & 1.70 to 9.0 & 0.00 \\
\hline Listening to music & 1.43 & 0.86 to 2.39 & 0.17 \\
\hline Other & 1.89 & 0.73 to 4.95 & 0.19 \\
\hline In a group, talking & 1.35 & 0.84 to 2.16 & 0.22 \\
\hline Female gender & 1.52 & 1.12 to 2.05 & 0.00 \\
\hline \multicolumn{4}{|l|}{ Age group } \\
\hline$<18$ years & 1.39 & 0.56 to 3.63 & 0.46 \\
\hline 18-24 years & Ref. & & \\
\hline $25-44$ years & 1.10 & 0.73 to 1.67 & 0.66 \\
\hline $45-64$ years & 0.74 & 0.46 to 1.20 & 0.22 \\
\hline $65+$ years & 0.57 & 0.28 to 1.17 & 0.13 \\
\hline
\end{tabular}

are disproportionately injured in crashes. However, previous observational studies suggest that before and during crossing, men were more focused on looking at vehicles than were women, who tended to focus on traffic lights and other individuals at the crosswalk. ${ }^{27}$ The higher rate of pedestrian injuries in males may be related to other risky behaviour, such as intoxication, crossing midblock and crossing arterials at night.

Recent work indicates that young people may display compulsive behaviours around mobile device use, which may make it more difficult to curb their use in contexts where it is unsafe, such as driving or crossing the street. ${ }^{28}$ This compulsive use of cell phones was also associated with higher reported crash rates. ${ }^{28}$

This study has strengths as well as limitations. We observed a large number of pedestrians under normal conditions, at a wide range of intersections. The unobtrusive nature of the study was designed to capture pedestrian behaviour. As a consequence, we estimated pedestrian age. The presence of an observer may have been noted by an alert pedestrian, who may have potentially altered his or her crossing behaviour. If this occurred, it is likely that the true prevalence of distraction may be higher than reported. The study was conducted in one Northwest city, and results may not be representative of other locales. Observation time windows may have favoured working-age individuals. This study analysed pedestrian risk behaviours such as disregarding traffic signals, but we are not able to link these behaviours to the risk of injury. We saw little evidence of highly risky pedestrian behaviour, such as running between moving vehicles, and conducted all observations during daylight hours. However, even moderately risky behaviours such as crossing against or close to the lights have been correlated with risk of injury eight times that of legal crossings. $^{29}$

Pedestrian distraction in general, and text messaging in particular, is associated with slower crossing times and unsafe pedestrian behaviours. The steady rise in the prevalence of text messaging and the use of mobile devices for a wide range of functions such as playing games suggests that the risk of distraction will increase. Solutions are likely to include the three 'Es' of injury prevention: education of the public about risks, engineering and environmental modifications, and enforcement. Published surveys and the lay press suggest that drivers ${ }^{10} 30-32$ and pedestrians ${ }^{33}{ }^{34}$ understand the risk of doing other 
activities while using mobile devices, believe that others should comply with the law, but continue to use devices. Individuals may feel they have 'safer use' than others, view commuting as 'down time', or have compulsive behaviours around mobile device use. ${ }^{10} 283132$ Environmental modifications which separate pedestrians from traffic and promote safe crossing may be even more important in an era of growing distraction. While individuals do not feel 'at risk' for relatively rare events such as injury, ${ }^{35}$ they may feel 'at risk' for a distraction citation if there is visible evidence of effective enforcement, as is being considered in some US cities. ${ }^{36} 37$ Ultimately, a shift in normative attitudes about pedestrian behaviour, similar to efforts around drunk driving, will be important to limit the state-dependent risk of mobile device use.

\section{What is already known on this topic}

Pedestrian actions may account for $15 \%$ of pedestrian fatalities.

- Talking on the phone while crossing the street impacts pedestrian behaviour. Cell phone use is associated with slower crossing times and fewer cautionary behaviours.

- Simulation studies suggest text messaging also increases pedestrian risk.

\section{What this study adds}

A total of $29.8 \%$ of pedestrians were using a mobile device during street crossing, and $7.3 \%$ were actively texting.

- Pedestrians who were text messaging displayed the highest risk of all distracted walkers, with slower crossing times and failure to display cautionary crossing behaviours.

- Pedestrians who cross against the traffic signal are more likely to look left and right than those who follow the traffic signals.

Acknowledgements We would like to thank Craig Moore and Vincent Prince from the Seattle Department of Transportation for their assistance in obtaining traffic flow and pedestrian crash data. Support provided by the Harborview Injury Prevention \& Research Center, Seattle, Wash.

Contributors BEE conceived of the study. LLT, BEE and FPR designed data collection tools and planned the study. LLT pilot tested study instruments and LLT and RCA collected study data. BEE analysed the data, and the analytic plan and findings were reviewed with all coauthors. LLT drafted the manuscript. BEE, FPR and RCA revised the draft manuscript.

Funding This research received no specific grant from any funding agency in the public, commercial or not-for-profit sectors.

Competing interests None.

Ethics approval Seattle Children's Research Institute.

Provenance and peer review Not commissioned; externally peer reviewed.

Data sharing statement All collected study data have been summarised and published in this manuscript. Interested parties who wish to request access to disaggregated and deidentified data for meta-analysis or other purposes are welcome to request access from the corresponding author.

Open Access This is an Open Access article distributed in accordance with the Creative Commons Attribution Non Commercial (CC BY-NC 3.0) license, which permits others to distribute, remix, adapt, build upon this work non-commercially, and license their derivative works on different terms, provided the original work is properly cited and the use is non-commercial. See: http://creativecommons.org/licenses/by-nc/3.0/

\section{REFERENCES}

1. Centers for Disease Control \& Prevention. WISQARS (Web-based Injury Statistics Query and Reporting System). [web page]. 2012. http://www.cdc.gov/ ncipc/wisqars/. (accessed 30 May 2012).

2. Naci H, Chisholm D, Baker TD. Distribution of road traffic deaths by road user group: a global comparison. Inj Prev 2009;15:55-9.

3. Sidewalks, crosswalks - Pedestrians, bicycles. In: Legislature WS. ed Vol RCW 46.61.2612010 http://apps.leg.wa.gov/RCW/default.aspx?cite=46.61.261 (accessed 30 Nov 2012).

4. Crosswalks. In: Legislature WS. edVol RCW 46.61.2352010.

5. Bungum TJ, Day C, Henry LJ. The association of distraction and caution displayed by pedestrians at a lighted crosswalk. J Community Health 2005;30:269-79.

6. Cinnamon J, Schuurman N, Hameed SM. Pedestrian injury and human behaviour: observing road-rule violations at high-incident intersections. PLoS One 2011;6:e21063.

7. Blodget H. The Future of Mobile: Mary Meeker, Kleiner Perkins Morgan Stanley Research via Business Insider; March 212012.

8. CTIA. CTIA Media: Wireless Quick Facts. 2011. http://www.ctia.org/media/ industry info/index.cfm/AID/10323 (accessed 15 Aug 2012).

9. ITU. Mobile cellular subscriptions, 2011. International Telecommunication Union, 2012. http://www.itu.int/ITU-D/ict/statistics/explorer/index.html (accessed 15 Aug 2012)

10. National Safety Council. National Safety Council Estimates that At Least 1.6 Million Crashes Each Year Involve Drivers Using Cell Phones and Texting [updated for 2011]. 2011. http://www.nsc.org/Pages/NSCestimates16millioncrashescaused bydriversusingcellphonesandtexting.aspx (accessed 15 Aug 2012).

11. Garner AA, Fine PR, Franklin CA, et al. Distracted driving among adolescents: challenges and opportunities. Inj Prev 2011;17:285.

12. Drews FA, Yazdani $\mathrm{H}$, Godfrey $\mathrm{CN}$, et al. Text messaging during simulated driving Hum Factors 2009;51:762-70.

13. Collet C, Guillot A, Petit C. Phoning while driving II: a review of driving conditions influence. Ergonomics 2010;53:602-16.

14. Collet C, Guillot A, Petit C. Phoning while driving I: a review of epidemiological, psychological, behavioural and physiological studies. Ergonomics 2010;53:589-601.

15. Consiglio W, Driscoll P, Witte M, et al. Effect of cellular telephone conversations and other potential interference on reaction time in a braking response. Accid Anal Prev 2003;35:495-500.

16. Hosking SG, Young $\mathrm{KL}$, Regan MA. The effects of text messaging on young drivers. Hum Factors 2009;51:582-92.

17. Lee JD, Roberts SC, Hoffman JD, et al. Scrolling and driving: how an MP3 player and its aftermarket controller affect driving performance and visual behavior. Hum Factors 2012;54:250-63.

18. Young KL, Salmon PM, Cornelissen M. Distraction-induced driving error: an on-road examination of the errors made by distracted and undistracted drivers. Accid Anal Prev 2012. Published online 22 June 2012

19. Virginia Tech Transportation Institute. New Data from VTTI Provides Insight into Cell Phone Use and Driving Distraction. July 272009.

20. Hatfield J, Murphy S. The effects of mobile phone use on pedestrian crossing behaviour at signalized and unsignalized intersections. Accid Anal Prev 2007;39:197-205.

21. Nasar J, Hecht $P$, Wener R. Mobile telephones, distracted attention, and pedestrian safety. Accid Anal Prev 2008;40:69-75.

22. Schwebel DC, Stavrinos D, Byington KW, et al. Distraction and pedestrian safety: how talking on the phone, texting, and listening to music impact crossing the street Accid Anal Prev 2012;45:266-71.

23. Stavrinos D, Byington KW, Schwebel DC. Effect of cell phone distraction on pediatric pedestrian injury risk. Pediatrics 2009;123:e179-85.

24. Stavrinos D, Byington KW, Schwebel DC. Distracted walking: cell phones increase injury risk for college pedestrians. J Safety Res 2011;42:101-7.

25. Neider MB, McCarley JS, Crowell JA, et al. Pedestrians, vehicles, and cell phones Accid Anal Prev 2010;42:589-94

26. Styns F, van Noorden L, et al. Walking on music. Hum Mov Sci 2007:26:769-85

27. Tom A, Granie MA. Gender differences in pedestrian rule compliance and visual search at signalized and unsignalized crossroads. Accid Anal Prev 2011; 43:1794-801.

28. Whitehill JM, O'Connor SS, King KM, et al. Compulsive cell phone use and risk of motor vehicle crash in young drivers. Pediatric Academic Societies Meeting; 2012.

29. King MJ, Soole D, Ghafourian A. Illegal pedestrian crossing at signalised intersections: incidence and relative risk. Accid Anal Prev 2009:41:485-90.

30. Collet C, Guillot A, Petit C. Phoning while driving I: a review of epidemiological, psychological, behavioural and physiological studies. Ergonomics 53:589-601.

31. Smith A. Americans and their cell phones. Pew Research Center, Washington DC, 2011. http://www.pewinternet.org/ /media//Files/Reports/2011/Cell\%20Phones\% 202011.pdf (accessed 30 Nov 2012)

32. Madden M. Adults and cell phone distractions. Pew Research Center, Washington DC, 2010. http://www.pemco.com/about us/Pages/ Jaywalkers deserve consequences.aspx (accessed 30 Nov 2012).

33. PEMCO. Jaywalkers Deserve Consequences. PEMCO Poll 2011. http://www.pemco.com about us/Pages/Jaywalkers deserve consequences.aspx (accessed 10 Aug 2012). 
34. Lowy J. Distracted walking: Smartphone-wielding pedestrians stumble into danger Christ Sc Monit 2012. http://www.csmonitor.com/USA/Latest-News-Wires/2012/ 0730/Distracted-walking-Smartphone-wielding-pedestrians-stumble-into-danger. No page/vol listed. (accessed 15 Aug 2012).

35. Lerner N, Singer J, Huey R. Driver strategies for engaging in distracting tasks using in-vehicle technologies. Washington, DC: National Highway Traffic Safety Administration, 2008
36. Melwert J. Distracted walking risks have lawmakers considering regulations. CBS Philly 2012. http://philadelphia.cbslocal.com/2012/07/31/distracted-walking-risks have-lawmakers-considering-regulations/ (accessed Aug 2012).

37. Administration NHTS. New Research Shows Enforcement Cuts Distracted Driving. 2012. www.nhtsa.gov/About+NHTSA/Press + Releases/2011/New + Research +Shows + Enforcement+Cuts + Distracted+Driving (accessed 15 Aug 2012).

\section{Important paper in prestigious journal}

Although we do not make a habit of calling attention to papers in rival journals, some exceptions always apply. A recent issue of the NEJM includes a paper entitled 'Injuries' by Robyn Norton and Olive Kobusingye, that is well worth reading. Congratulations to Robyn and Olive.

N Engl J Med 2013; 368:1723-1730. 2 May, 2013, doi:10.1056/

http://www.nejm.org/doi/full/10.1056/NEJMra1109343?query=TOC

\section{Bangladesh's garment worker death toll rises}

The Wall Street Journal reports that following the collapse of a building housing factories that made low-cost clothes for western brands, the death toll is now more than 1100. Local officials said the eight-storey building, Rana Plaza, was constructed without proper permits. The owner, a local politician, bypassed the building safety agency and obtained permission from the mayor to build the complex. At least two garment factories at Rana Plaza had passed international labour and safety standard audits by a European trade organisation, but the audits did not assess the stability of the building.

\section{Settlement resolves Federal Aviation Administration probe of aircraft problems}

American Airlines' (AA) agreement to pay $\$ 24.9$ million sweeps away proposed fines of $\$ 162$ million previously sought by the Federal Aviation Administration (FAA). American, its American Eagle regional affiliate, and two other subsidiaries denied wrongdoing but agreed to the settlement. Among the issues covered was the 2008 grounding of an aircraft with suspect wiring problems resulting in the cancellation of thousands of flights. The FAA said American crews failed to follow proper procedures, raising the risk of fires and fuel tank explosions (The Associated Press).

\section{Road Traffic Injuries Research Network workshop in Brazil}

As part of the Road Traffic Injuries Research Network's (RTIRN) efforts in capacity development in low and middle income countries, 30 participants attended a two-day regional workshop that was held in Curitiba, Brazil. The aim was to increase knowledge and experience in the use and implementation of tools to monitor and evaluate road safety interventions. Participants shared their experiences, challenges and approaches to problem solving in implementing road safety activities.

http://www.rtirn.net/2013_RTIRNregional

Workshop.asp 